\title{
TEATRO TESTIMONIAL: UNA PROPUESTA DE EDUCACIÓN INTERCULTURAL
}

\author{
TESTIMONY THEATRE: AN INTERCULTURAL \\ EDUCATION PROPOSAL
}

\author{
Natascha Diharce Böser*
}

\begin{abstract}
El presente artículo tiene por objetivo reflexionar en torno a las posibilidades de inserción del enfoque intercultural en prácticas educativas más allá del aula, centrándose en las artes escénicas. Para esto haré una introducción al enfoque intercultural y su aplicación en educación, expondré la relación existente entre la educación intercultural y el arte dramático, presentaré al teatro intercultural y lo intercultural en el teatro, para finalizar describiendo algunas características del proceso creativo desarrollado por la Compañía de Teatro KIMEN, como una de las tantas posibilidades de educación intercultural.
\end{abstract}

Palabras claves: Educación intercultural, teatro testimonial, enfoque intercultural, Teatro Kimen, Ñi Pu Tremen.

The objective of the present is to reflect upon the possibilities of inclusion of the intercultural approach in educational practices beyond the classroom, focusing on dramatic arts. I will make an introduction into the intercultural approach and its application in education, exposing the relationship between intercultural education and the dramatic arts. This will be made by presenting the intercultural theatre and what I consider to be the intercultural characteristic present in the dramatic practice. I will finish describing some characteristics of the creative process developed by the Theater Company called Teatro Kimen as one of many possibilities for an intercultural education

Key words: Intercultural education, testimony theatre, intercultural approach, Teatro Kimen, Ni Pu Tremen.

\section{Introducción: \\ Enfoque intercultural en educación}

Que ninguna cultura es intrínsecamente superior a otra es el punto de partida del enfoque intercultural y esta promueve comenzar a pensar, ser y actuar a partir de ella. Más aún, gestiona reflexiones y acciones -considerando que las relaciones culturales existentes poseen estructuras de poder dominantes y relaciones asimétricas- para readecuar esas relaciones hacia un equilibrio social y cultural. Desde esta perspectiva, al hablar del enfoque intercultural es preciso declarar que el concepto se utiliza para definir una forma de pensar y actuar en sociedad, a pesar de que lo intercultural también podrá ser definido en función de las múltiples acepciones que el concepto de cultura posea.

Es por esto que uno de los espacios concretos donde se aplica el enfoque intercultural es el de la educación, por el impacto que provocan los procesos educativos formales e informales en la formación de las personas. En alguna medida toda interacción se convierte en un espacio de aprendizaje y por lo mismo, cuando participamos de procesos educativos debemos considerar que esos espacios son en sí mismos un ejemplo del tratamiento de la diversidad existente, lo que genera la necesidad de considerar todas las formas de ver y hacer en la cotidianeidad, para promover un diálogo que disminuya las asimetrías. Como se señala en la Guía INTER. Una guía práctica para aplicar la educación intercultural en la escuela:

Hablaremos de diversidad cultural para referirnos a todo el conjunto de estrategias, normas y valores que los seres humanos han sido capaces de desarrollar para vivir en grupo, y como grupo adaptarse a distintos entornos, a lo largo del tiempo y del espacio. Estas estrategias, normas y valores se han convertido en costumbres y de esta forma son compartidas por un grupo de personas, cuyos miembros orientan su comportamiento de acuerdo con ellas y las enseñan a sus descendientes (Aguado et al., 2002:211).

La diversidad cultural es entonces la premisa sobre la que el enfoque intercultural plantea su

* Universidad Nacional de Educación a distancia (UNED), España. Correo electrónico: ndiharce1@alumno.uned.es 
discurso y acciones, en tanto que la educación intercultural la entenderemos como:

Una práctica, una forma de pensar y hacer que entiende la educación como transmisión y construcción cultural; que promueve prácticas educativas dirigidas a todos y cada uno de los miembros de la sociedad en su conjunto; que propone un modelo de análisis y de actuación que afecte a todas las dimensiones del proceso educativo. Los objetivos de esta educación son la igualdad de oportunidades -entendida como oportunidades de elección y de acceso a recursos sociales, económicos, educativos-, la superación del racismo y la adquisición de competencia intercultural (Aguado, 2008:1).

Este modelo nos propone reflexionar en torno a dinámicas insertas en nuestros imaginarios sociales, sobre los roles y funciones asignados a categorías de personas, y en el caso del aula, la relación entre alumnos y profesores, entre alumnos y sus contextos, y entre los contextos de todos los actores implicados en el proceso educativo. Un enfoque que nos invita a reparar en los procesos invisibles de las relaciones humanas y que por el mismo hecho de ser invisibles, muchas veces son desatendidos, lo que genera la emancipación de ideas y acciones que continúan obstaculizando la igualdad de oportunidades.

Es así como la educación intercultural plantea la incorporación de los múltiples contextos dentro del aula, para que los alumnos otorguen un significado particular al quehacer educativo. De esta forma el conocimiento o el acto de conocer, siempre tiene relación con el contexto en el que sucede y con las relaciones dentro de ese contexto. Siguiendo esta línea podemos decir que la educación intercultural y sus estrategias pedagógicas promueven visibilizar las formas orgánicas que poseen los seres humanos para construir conocimiento y relacionarse con otros seres humanos. Por lo que al evidenciar que la educación es una estrategia para conocer otros procesos de construcción de conocimiento, se aprovechan los espacios educativos para reproducir prácticas que dan sentido a esas experiencias y en conjunto crear una nueva forma de construirlo, en estos espacios educativos.

El aprendizaje es una acción que involucra al cuerpo, y ese cuerpo carga una historia, por tanto, el aprendizaje se convierte en la acción de poner a interactuar la historia personal con aquello que se estudia, y que utiliza nuestra experiencia como trampolín hacia la generación de sentido, como una flecha que dirige nuestro camino.

\section{Educación intercultural y artes escénicas}

Uno de los lugares donde podemos observar si efectivamente nuestra visión de mundo contempla la diversidad cultural, es el espacio de la comunicación, en cualquiera de sus formas. Y como ya se ha dicho en numerosas oportunidades, el lenguaje construye realidad y al expresarnos, verbal, corporal o sígnicamente, dejamos de manifiesto nuestra forma de ver el mundo. Por este motivo, considero esencial observar los múltiples espacios de comunicación humana y pensar en las formas que utilizamos para comunicarnos, particularmente los medios para comunicarnos -donde incluyo a las artes y las prácticas teatrales en particular-. Las artes deben ser sometidas al mismo análisis crítico del que son sujetos otros medios de comunicación, ya que poseen la misma responsabilidad social, como intermediarios entre los sucesos sociales y las audiencias. Al respecto, Besalú manifiesta que:

El mundo de las imágenes, tan presente en el mundo de hoy y a través de tan variados formatos, no representa únicamente un poderoso centro de atracción e interés, sino también uno de los ejes en torno al cual articular un planteamiento intercultural: la publicidad, la televisión, la fotografía, el cine, la cámara de grabación, las instalaciones, las performances... ofrecen una amplísima gama de herramientas con las que comprender y representar el mundo. (Besalú, 2010:18)”.

Las artes son en sí mismas medios de transmisión cultural, donde las creaciones provienen de las experiencias o el imaginario de los creadores, cargados de significados que comparten con sus pares artistas, pero también de elementos constitutivos de su identidad individual y colectiva, dentro de un contexto o varios. Particularmente, el arte dramático es el lugar donde de modo más tangible podemos observar representaciones culturales, ya que se ponen en escena sensaciones, emociones y representaciones colectivas, mediante el lenguaje 
escénico, lo que sería un símil de las formas cotidianas que tenemos de relacionarnos, generando un diálogo con las representaciones culturales propias de las audiencias presentes en el acto comunicativo, lo que de por sí se constituye como un proceso educativo. Como lo menciona Aristóteles (2009), las artes son técnicas de reproducción de la realidad, variadas en sus formas, estilos y medios de imitación, pero con un objetivo común que sería manifestar una idea respecto de lo observado y provocar algo en los espectadores.

En esta tríada de la cultura, arte y educación podríamos inferir que las culturas, o formas de significación, nos entregan herramientas para guiar nuestra interpretación del mundo, mientras las artes nos enseñan mundos posibles -mediante el ejercicio de la creación y la recreación-, y finalmente la educación, se constituye como el lugar donde interactuamos y ponemos en escena nuestra forma de ver el mundo, y una forma de poner en escena esta conexión es mediante el aprendizaje situado como herramienta pedagógica, ya que, según Sagástegui:

...el aprendizaje situado exige en la escuela una actividad creativa de interpretación del mundo; requiere que los estudiantes operen en situaciones "reales" y "auténticas" semejando las formas de aprendizaje que se producen en la vida cotidiana, en donde los sujetos se encuentran inmersos en el marco de sentido de una cultura, interactuando con otros agentes humanos y con agentes no humanos..." (Sagástegui, 2004:33).

De esta manera, los procesos creativos de cualquier índole comienzan con un problema que debemos solucionar, continúan con un proceso de recopilación de información y de procesamiento de la misma, para pasar por la iluminación y terminar en la concreción de aquello que solucionará el problema. Y en todo este camino utilizaremos nuestras formas de pensar, estableciendo vínculos concretos a partir de aquello que conocemos y de lo que soñamos, por lo que siempre estaremos hablando de nosotros en relación con algo.

Específicamente el arte dramático trata contenidos en contexto, y es la representación de los individuos en contexto, y por lo mismo ofrece amplias posibilidades para el aprendizaje conjunto, sobre nuestras formas de relacionarnos. "La ficción nos permite explorar los límites de la condición humana, fisgar en la intimidad de las personas, descifrar lo que permanece oculto en nuestro interior, explorar otros universos morales..." (Besalu, 2010:16).

\section{El teatro intercultural}

Para Pavis "el teatro intercultural, en el sentido estricto, crea formas híbridas a partir de la mezcla más o menos consciente y voluntaria de tradiciones de actuación reconocibles en áreas culturales distintas" (Pavis, 1994:333). Podríamos decir que en esta idea, la acepción de interculturalidad está asociada a la mezcla o intercambio de elementos entre culturas y se suele asociar a prácticas que incorporan elementos del teatro oriental en el teatro occidental.

Lo que se incorpora de otras culturas, específicamente las orientales en el último tiempo, son elementos como el trabajo del cuerpo de los actores (técnicas corporales y vocales, de actuación y movimiento) y algunos elementos de la puesta en escena, como máscaras, instrumentos musicales o vestuarios; sin embargo, agregar estas formas de representación no significa necesariamente estar utilizando el enfoque intercultural.

Así como existen directores teatrales que utilizan este intercambio de elementos culturales en sus espectáculos, encontramos a otros que objetan su utilización de forma explícita, como Schechner, que al ser preguntado en una entrevista por qué prefirió utilizar elementos extranjeros de una manera más indirecta en su trabajo, este respondió que "[su]... objeción a utilizarlos está en que estas formas son muy particulares en su contenido, y no se las puede utilizar a menos que uno quiera apropiarse también de su contenido" (Schechner, 1994: 57).

Lo que plantea Schechner es que efectivamente al utilizar elementos propios de cualquier cultura, no debemos olvidar los significados que poseen y que hemos de hacernos responsables de esa carga simbólica.

Como podemos observar, existen varias posturas respecto del teatro intercultural, ya que también encontramos el trabajo de Peter Brook, quien desde hace algunas décadas está trabajando con actores provenientes de diversos países, que traen consigo las formas teatrales propias de sus culturas, por lo que en ese acto nace lo que Brook llama "la tercera cultura" o "la cultura de los lazos", que define como:

...la fuerza que puede contrarrestar la

fragmentación de nuestro mundo. Está 
ligada al descubrimiento de relaciones ahí donde tales relaciones se han sumergido o perdido -entre el hombre y la sociedad, entre una raza y otra, entre el microcosmos y el macrocosmos, entre la humanidad y la máquina, entre lo visible y lo invisible, entre las categorías, las lenguas y los géneros... (Brook, 1994:103).

Lo que Brook plantea es otra visión del teatro intercultural, ya que está en la búsqueda de un lenguaje universal del teatro, donde la incorporación de variados elementos culturales sobre el escenario no tendría como finalidad hacer un intercambio cultural, sino que por medio de la utilización de las múltiples formas que tienen de expresarse esos actores y objetos sobre el escenario, traspasa las limitaciones de las variadas lenguas y objetos, para apelar a la construcción de sentido de los espectadores desde formas construidas conjuntamente entre los creadores y audiencia, mediante un lenguaje universal. Desde esta perspectiva, Fisher-Lichte concibe lo siguiente:

Como solo se presentan al espectador objetos que no se limitan a la significación de una cultura específica, el espectador de cualquier cultura está en capacidad de percibir y de hacer significar los objetos presentados en el contexto de su propia experiencia cultural. La renuncia a todo proceso de signos en la escena condiciona la realización de los procesos de signos por el espectador, independientemente de la cultura a la que pertenezca (FischerLichte, 1994:42).

Las anteriores son algunas de las posibilidades de construcción de espectáculos interculturales, por lo que a continuación me propongo identificar aquellos elementos dentro del teatro, que considero analogías del enfoque intercultural, por lo que hablaremos de lo intercultural en el teatro.

\section{Lo intercultural en el teatro}

Utilizaremos el concepto de teatro para referirnos al espacio físico donde convergen dos o más culturas y que incluirá a actores/actrices y espectadores, en tanto que utilizaremos el concepto espacio escénico para referirnos a aquello que sucede sobre el escenario. El teatro como espacio físico es un lugar constituido a partir del cruce de significados entre los espectadores y los actores o actrices, por lo que desde esta definición tanto las culturas como el teatro, son un sistema de signos compartidos por individuos. Junto con esto, en el mismo espacio escénico nos encontramos con actores y actrices que dialogan entre sí, a partir de significados construidos colaborativamente durante el proceso creativo de la puesta en escena.

Es así como el espacio escénico existe gracias a la intervención de todos los participantes de la representación, incluidos los espectadores, ya que serán ellos quienes darán sentido a aquello que se presenta, por lo que si no existe alguien que observe el suceso, este carecerá de la idea esencial del teatro, esto es, poner en común. Para Peter Brook, "un hombre camina por un espacio vacío mientras otro le observa, y esto es todo lo que se necesita para realizar un acto teatral" (Brook, 2000:5).

Desde un punto de vista semiológico, el arte de la representación escénica se constituye basándose en signos que portan significados propios del contexto de donde provienen, pero que al pasar por el espacio escénico adquieren nuevas dimensiones, desde la relación actor-objeto, hasta la relación actor-objeto-espectador, ya que el mismo cuerpo del actor o actriz se convierte en un signo sobre el escenario. "Sobre un escenario teatral todo elemento vivo o inanimado del espectáculo se ve sometido a semejante inflexión, es vuelto a trabajar, citado, inscrito dentro del conjunto significante de la puesta en escena y de la actuación del actor" (Pavis, 1994: 326).

En última instancia, el espacio escénico es una construcción visual, emocional, sensorial y energética compartida y creada por los que están dentro y fuera del escenario, a partir del valor otorgado a lo que ahí sucede, provocando la amplitud de lo representado, y a esa amplitud llamaremos teatralidad.

Lo teatral o la teatralidad suceden en un espacio donde se concentran e intercambian puntos de vista o visiones de mundo. Pero ¿qué es lo que sucede cuando existe un espacio que permite que las miradas de distintas personas se crucen?, ¿dónde miramos cuando tenemos la posibilidad de hacerlo, en un espacio que nos invita y dirige la mirada, como espectadores? Esto se volvería un caos en el caso de no dirigir la atención de los espectadores, ya que la percepción y particularmente la atención se pueden centrar en múltiples lugares en forma simultánea. 
Lo teatral tiene muchas acepciones, pero podríamos decir que es aquello que ilumina o amplía un suceso, y esto eventualmente ocurre gracias a la colaboración del sistema de signos escénicos y extraescénicos, que dan vida al espacio escénico. Lo teatral se vale de la utilización de herramientas del lenguaje teatral, como elementos constitutivos de un acto comunicativo de cualquier índole, por lo que cuando se dice: "estás siendo muy teatral", se está haciendo alusión a que se está ampliando y exacerbando la forma de comunicación cotidiana dentro de cualquier contexto.

Lo invisible de la representación es perceptible por otros sentidos, ya que la experiencia que se obtiene en las distintas realidades, y la forma en que esas realidades se construyen, siempre será según los sentidos, por lo que el teatro al pretender la representación de la realidad, lo hace apelando a todos los sentidos y no solo a la vista. Precisamente, a través de la visión abrimos la puerta a otros sentidos, como el audio y el olfato, pero existe una capa más profunda que va más allá de los sentidos y estas son las emociones, que provocan reacciones físicas concretas en los cuerpos de los espectadores. Según Barthes, la teatralidad:

...Es el teatro sin el texto, es un espesor de signos y sensaciones que se edifica en la escena a partir de un argumento escrito, esa especie de percepción ecuménica de los artificios sensuales, gestos, tonos, distancias, sustancias, luces, que sumerge el texto bajo la plenitud de su lenguaje exterior... (Citado en Arana Grajales, 2007:80).

La teatralidad es la exposición de aquello que habitualmente no vemos, es la exacerbación de lo invisible y de vital importancia a la hora de relacionarnos, y que permite la aparición de mundos sensibles, que de otra forma no tendrían espacio para manifestarse. Ahora bien, ¿dónde sucede lo intercultural en el teatro?

\section{Relación actores-espectadores y relación actores-actrices}

Lo intercultural sucede, en primera instancia, en el diálogo o acuerdo tácito que existe entre actores y espectadores, donde los comportamientos de ambas partes están definidos a priori. Los espectadores aceptan ingresar a un espacio donde les hablarán de algún tema o les mostrarán la historia de vida de un grupo, y ellos sin objeción, y más aún, pagando un precio por ello, acceden a escuchar. $\mathrm{Y}$ al aceptar están dispuestos a que algunas ideas sean insertadas en su imaginario, ya que finalmente, todo acto comunicativo posee la característica de la persuasión, pero más allá de persuadir, lo que aparece en el escenario es creado de forma artificial, pero ejecutado de manera tal que se transforma en una realidad presente y viva, por lo que limita las posibilidades de juzgar, ya que hemos decidido ingresar al mundo de la ficción, dejando de tener plena conciencia de nuestros propios contextos, y que solo volveremos a estos -como espectadorescuando algo del espectáculo nos remita a ello. Y son justamente esos momentos de vinculación entre la representación y la vida de los espectadores, los que generan una posible apertura a nuevas formas de entender el mundo y desde ahí experimentar lo intercultural en el teatro.

Ahora lo veremos desde otra perspectiva, desde la relación de los creadores hacia los espectadores. Anne Ubersfeld presenta al espectador como "el destinatario del discurso verbal y escénico, el receptor del proceso de comunicación, el rey de la fiesta..." (Ubersfeld, 1996:305). Todo lo que se construye en el proceso creativo de un montaje teatral está supeditado por la mirada de los posibles espectadores, ya que se crea en función de los procesos cognitivos, emocionales, políticos y sociales del contexto al que pertenece la audiencia que asistirá a la representación. ¿Por qué se hace esto? Porque es necesario que alguien decodifique todos los signos presentados en el escenario, pero que los decodifique en función del mensaje del/a director/a y la compañía, por lo que aparece un campo más complejo y que podría eventualmente dar cabida al enfoque intercultural. Los creadores teatrales elaboran un discurso o premisa, y después investigan las posibilidades de interpretación o de sentido que podrían asignar los espectadores a ese discurso, para seleccionar y ordenar las piezas del discurso -ideológico y escénico- en función de las formas de interpretación de las audiencias.

Esto refleja la importancia de la visión de mundo de las audiencias en la construcción de relatos desde el aparataje teatral, lo que sitúa tanto a los creadores como a los espectadores en una relación idealmente simétrica de construcción de sentido, ya que también existe un vacío respecto de las posibles interpretaciones de ambos. 
En este sentido, los otros (espectadores) no presentes físicamente en el proceso creativo, son agentes activos de la creación, debido a que es en función de ellos y sus formas de significar que se integrarán y articularán los componentes de la puesta en escena, para de esta forma guiarlos hacia la premisa de dirección, pero siempre desde la mirada de los espectadores.

\section{Relación entre actores y actrices: técnicas de actuación}

El otro lugar donde aparece el enfoque intercultural es en el ejercicio de la actuación. Existen múltiples técnicas de actuación, algunas de ellas construidas para universalizar este lenguaje, y otras con fines más políticos, que pretenden transformar, por medio de la actuación, ciertos aspectos de la sociedad. Sin embargo, existe un elemento común a cualquier estilo de actuación que tiene relación con la interacción entre actores y la forma en que se comunican entre sí. Al descomponer a los actores entre lo que son y lo que hacen sobre el escenario, podemos decir que lo que son -o su identidadmuchas veces aparece de forma involuntaria o escapa a su conciencia, debido al alto grado de exposición en que se encuentran. De hecho, el arte de la actuación nace como una necesidad de tomar conciencia de todo lo que el ser humano es, para poder canalizarlo en beneficio del espectáculo.

Ubersfeld plantea que “... [El comediante] es productor de signos que no ha querido producir: el timbre o el "tono" de su voz, su estatura, la forma de sus rasgos, el aura que lo envuelve, los otros papeles que ha interpretado, etc." (Ubersfeld, 1996:172). Todos los elementos recién mencionados son parte de la cultura de los actores, por lo que esos elementos existen y se manifiestan en los procesos creativos teatrales. Es por esto que cuando aparecen dos actores/actrices dialogando sobre el escenario es necesario, en beneficio de la verosimilitud de lo representado, que en ese diálogo flexibilicen su mirada para permitir la entrada de la mirada del/a otro/a.

Muchos teóricos de la actuación dicen que el mejor actor es aquel que reacciona frente a su compañero y no aquel que está preocupado de su propio texto o momento sobre el escenario. Y es en ese lugar donde yo observo que aparece el enfoque intercultural, por cuanto aquello que el actor debe comunicar-como productor/a de signos dentro del espectáculo teatral- debe estar siempre en armonía con el otro actor; en otras palabras, se debe actuar desde la perspectiva del otro, porque de lo contrario quedará en evidencia que el actor está superponiendo su visión o interpretación por sobre la de su compañero/a.

Es prácticamente lo mismo que sucede en la relación entre los creadores y las audiencias, pero en un nivel micro, porque sucede dentro de los representantes del discurso escénico y que por supuesto exige comprender y valorar las formas de significar que poseen todos los participantes en el proceso dentro del escenario, ya que en ese momento ambos son signos propios de diferentes culturas, pero que desean construir un discurso común, por lo que en ese intercambio físico, emocional, espiritual, político y social, representan un ejercicio de comunicación intercultural.

\section{Teatro Kimen: Una experiencia de teatro documental-testimonial como ejercicio de educación intercultural}

Anteriormente observamos donde podemos identificar el enfoque intercultural en la práctica teatral, ahora conoceremos qué estilo teatral podría facilitar o generar opciones de educación intercultural en su ejecución y este es el teatro documental o testimonial. Este estilo tiene por objetivo poner en escena un documento o testimonio proveniente de diversas fuentes, y que una vez situado en el espacio escénico genera un diálogo con la audiencia, ya que "lo documental no está en el objeto, sino en la relación entre el objeto [o testimonio], sus mediadores (artistas, historiadores, autores) y su audiencia" (Reinelt, 2011:7).

El montaje del testimonio funciona como una reconstrucción de escena, por lo que las variantes invocadas desde el suceso original pueden adquirir nuevas connotaciones, tanto en la representación, como en los espectadores del relato; a la vez que provoca una reflexión sobre la "búsqueda de la verdad" contenida en el documento, ya que este solo proporciona un punto de partida o un punto de vista desde donde comprender un fenómeno, por lo que los elementos del contexto son de gran importancia en la reconstrucción documental.

En Santiago de Chile existe una compañía de Teatro llamada KIMEN, cuyo trabajo es de corte documental-testimonial y dentro de sus obras se encuentran: "Ñi Pu Tremen. Mis antepasados", 
“Territorio Descuajado" y "Galvarino". A continuación describo y reflexiono sobre algunos de los elementos más característicos de dos de sus montajes ("Ni $\mathrm{Pu}$ Tremen. Mis antepasados" y "Galvarino"), porque considero que son un claro ejemplo de cómo el teatro documental-testimonial puede promover la educación intercultural.

\section{Anónimos actores y actrices}

Una de las particularidades de Teatro KIMEN es que en su mayoría han desarrollado montajes donde no han actuado actores de profesión y donde la actuación está a cargo de los mismos testimoniantes de los relatos -en el caso de "Ñi Pu Tremen"-; mientras que en su montaje llamado "Galvarino", las actuaciones están a cargo de personas sin formación actoral, pero que poseen algún vínculo cercano con aquellos a quienes representan, mediante el testimonio.

A los actores de estos trabajos he decidido llamarlos anónimos actores. En primer lugar, porque considero que no es necesario pasar por una institución formal para aprender técnicas de actuación para ser actor o actriz. De hecho, una de las grandes premisas del teatro -como acto comunicativo- ha sido la de convencer a la audiencia sobre la verosimilitud de los hechos y palabras que están presenciando, o que lo que se está observando sea lo más real posible y para esto, los actores profesionales estudian una gran cantidad de técnicas que faciliten la representación de la realidad de la manera más verdadera posible, lo que no implica necesariamente que se logre el tan ansiado efecto de la identificación en los espectadores, por lo que en alguna medida todos somos actores en nuestras sociedades, unos más públicos y otros más anónimos.

En segundo lugar, me parece fundamental lo anónimo de estos actores y actrices sociales y sus testimonios en el impacto de este tipo de trabajos, ya que se construyen relatos o se ponen en escena historias de quienes no han tenido voz, y también porque de alguna manera el teatro convencional, o el teatro construido mediante la ficción, representa esas voces, pero poniendo el énfasis en los aspectos técnicos del montaje. Sin embargo, el solo hecho de abordar algunos temas en el teatro no asegura que la realidad de esas personas de quienes se habla, cambie o mejore, o peor aún, que aquellos de quienes se habla logren siquiera asistir a las representaciones que hablan de ellos, y que se los esté representando de la forma más fiel posible. Por último, la característica de no ser actores de profesión provoca un acercamiento más íntimo entre los actuantes y los oyentes del acto comunicativo teatral, promoviendo una forma de relación más simétrica y efectiva, alejada de tecnicismos.

\section{La puesta en escena o teatralización de testimonios}

Para realizar un análisis de la puesta en escena de una obra de teatro es indispensable plantear la complejidad de tal tarea, primero, porque existe una cultura de análisis semiológico teatral que se utiliza comúnmente para desglosar los espectáculos a partir de los signos y significados de todas las capas del lenguaje escénico. Y considerando que los significados culturales otorgados a experiencias, objetos o documentos, responden a innumerables factores, reducirlos a categorías fijas sería incongruente.

Patrice Pavis (2000) plantea esta reflexión a partir de lo que conocimos en su definición del teatro intercultural, que considera los espectáculos conformados por el cruce entre prácticas teatrales orientales y occidentales; sin embargo, lo que nos interesa comprender aquí es el sistema construido por los elementos en los montajes de KIMEN, que no son producto del cruce recién mencionado, sino que son un producto construido entre las creadoras de la compañía y las mujeres miembros de una comunidad mapuche-urbana, en el caso de Ñi Pu Tremen.

De esta manera, podríamos hablar de un modelo intercultural de análisis del espectáculo teatral, donde el ejercicio es entender desde quienes comunican aquello que desean comunicar, y desde esta perspectiva el aprendizaje se vuelve significativo y complejo a la vez. Significativo porque hay elementos que inevitablemente poseerán un significado para las audiencias, que escapa quizás a la misma intención de las creadoras, considerando que finalmente el producto solo existirá en la medida que alguien lo recepcione y lo resignifique; y complejo, porque efectivamente nos abre un mundo de oportunidades para comprender algo más allá de lo evidente. Es por esto que la mejor herramienta para analizar la puesta en escena es rehacer el proceso creativo de la compañía y detenerse en aquellos momentos o experiencias en que ellas hayan reparado, siguiendo a Pavis (2000:293) quien plantea que "este modo de 
proceder también proporciona información sobre la manera de narrar, propia de cada cultura, con los ejemplos que considera necesarios y en función de las dificultades y la originalidad de sus propias manifestaciones".

\section{Reconstruyendo el proceso creativo de la Compañía Ni Pu Tremen}

Para comenzar con la construcción del relato sobre la vida de Galvarino, las fundadoras de la compañía entrevistaron a su hermana, y durante esas sesiones ella mostró algunas cartas que había recibido de su hermano desde Rusia ${ }^{1}$. El testimonio en sí era bastante breve, por lo que la dramaturga se interesó en la personalidad de Marisol, identificando los temas centrales extraídos de la entrevista y basándose en estos hitos centrales se reconstruyó una escena donde este testimonio estuviera presente. El registro y las huellas propias de haber sido testigo o protagonista de un suceso pueden instalarse tanto en los cuerpos como en objetos. Es así como un espacio físico también es testimonio de la forma de vida de un grupo y en él se pueden materializar fragmentos de su realidad. Desde el espacio físico se puede recordar, en forma de fragmentos muchas veces inconexos, emociones de sucesos vividos o soñados, por lo que se constituye como una gran herramienta para poder captar la realidad como la vivimos, donde convergen múltiples personajes, acciones y objetos en forma simultánea.

Una vez obtenidos los testimonios se necesitaba definir un espacio físico donde se relaten los acontecimientos, para después seleccionar acciones que acompañen el relato. Por ejemplo, para la puesta en escena de "Galvarino", decidieron recrear la cocina de una casa de campo del sur de Chile con todos sus elementos y a partir de eso se construyó una pauta de acciones de lo que ocurriría en escena. Estas acciones serían interpretadas por los anónimos actores y actrices, por lo que al momento de ejecutarlas, automáticamente aparecían formas de hacer y de ser de los anónimos, en relación con los objetos y acciones presentes. Esto deja en evidencia que si bien los anónimos actores pueden no conocer técnicas propias del lenguaje teatral, tienen sus propias formas de construir realidades, lo que sería la tarea final del teatro, con la única salvedad que en el teatro testimonial realizado por KIMEN la realidad es construida a partir de anónimos y con anónimos.

\section{Las acciones y los objetos}

Una vez descubierto el contexto donde sucederá el testimonio, se procede a seleccionar acciones propias de ese espacio físico, por lo que buscaron acciones cercanas a los actores y actrices. En el caso de la Sra. Elsa (actriz que interpreta a la madre de Galvarino en la obra "Galvarino"), ella realizó la acción de cocinar una gallina, desde el proceso de quitarle las plumas -una vez muerta- hasta cocinarla en escena ${ }^{2}$. Esta acción fue bastante emblemática para las cocreadoras, debido a que en la actualidad existen muchos grupos proanimales, por lo que se cuestionaron bastante antes de decidir utilizarla ${ }^{3}$. Sin embargo, el impacto provocado en la audiencia no fue negativo, porque comprendieron la acción en su contexto, ya que esta acción es común en las familias que viven en el campo del sur de Chile; lo interesante de esto es que aparece otra forma de aprendizaje desde el teatro testimonial: la comprensión de acciones y relaciones en contexto.

En cuanto a las acciones que realizaría el hombre de la obra, se optó por la confección de una trampa para conejos ${ }^{4}$, acción que comúnmente realiza el actor anónimo, y que es justamente el abuelo de la directora de la Compañía. Esa acción también porta información trascendental de la cultura a la que representa, por cuanto habla de actividades cotidianas de un lugar del sur de Chile.

\section{La lengua}

En términos del trabajo lingüístico dentro de los dos montajes, aparece la incorporación del mapudungun -lengua mapuche-, lo que genera un efecto muy interesante, ya que se podría pensar que sería un obstáculo para las personas del público que no hablamos mapudungun; sin embargo, no es necesario conocer el idioma para comprender lo que se quiere decir. Aquí es donde aparece aquello de lo que habla Peter Brook (1994) respecto del concepto de la "tercera cultura", ya que las herramientas comunicativas del teatro se convierten en un lenguaje universal que traspasa las barreras de las lenguas y tradiciones, por lo que estamos en presencia de experiencias humanas y emocionales que ayudan a comprender aquello que es relatado.

Finalmente, el testimonio se apodera de la totalidad de la puesta en escena, por lo que el espacio escénico se configura como el mundo del testimonio a relatar, y son las audiencias las encargadas de dar 
los múltiples sentidos posibles a la representación, pero siempre desde la mirada del otro.

\section{Conclusiones}

Las obras de teatro de corte testimonial proveen innumerables herramientas de educación intercultural, primero, porque el espacio teatral es un medio de transmisión cultural cuyas herramientas son propias de un lenguaje elaborado a partir de múltiples visiones de mundo, por lo que el teatro se constituye como una forma de construcción cultural colaborativa, donde los múltiples y simultáneos procesos de codificación y decodificación que suceden entre los participantes son construidos basándose en diálogo sin mediadores. En segundo lugar, incluye a todos los miembros de la sociedad; de hecho, otorga un espacio para aquellos miembros de la sociedad que no poseen muchas posibilidades de participar o tener parte en todos los procesos sociales.

Junto con esto se convierte en un acto educativo por las posibilidades de transformación que genera en quienes tienen la oportunidad de participar en cualquier momento de la producción o la recepción del testimonio, ya que si logramos corporizar una experiencia de vida y compartirla, podríamos eventualmente generar cambios en las percepciones y relaciones que establecemos con otras personas. En palabras de Maturana:

... La dificultad de los cambios de entendimiento, de pensamiento, de valores, es grande. Esto se debe a la inercia corporal y no a que el cuerpo sea un lastre o constituya una limitación... Más aún, el vivir transcurre constitutivamente como una historia de cambios estructurales en la que se conserva la congruencia entre el ser vivo y el medio, y en la que, por ende, el medio cambia junto con el organismo que contiene (Maturana, 2013: 67).

Otro de los aportes de este es la relación que se establece entre los testimoniantes y quienes observan o escuchan el testimonio, ya que el teatro es un espacio físico donde se reúnen dos grupos, quienes representan sobre el escenario y la audiencia.

Por último, si observamos la íntima relación existente entre los cambios sociales y los estilos artísticos que surgen a partir de esos cambios sociales en cualquier sociedad, el teatro testimonial podría ser una expresión fiel de una crisis en los modelos de representación social, ya que así como en las comunidades políticas, algunos representantes pierden de vista los intereses de las personas a quienes representan, las manifestaciones teatrales convencionales también incurren en el olvido de las personas a quienes representan, cegándose con las formas y encuentros estéticos que van teniendo con las distintas artes, hasta llegar a olvidar a los individuos y quedarse en el campo discursivo de las ideas.

Finalmente, por medio del teatro testimonialdocumental promovemos el reconocimiento de la diversidad cultural, nos hacemos cargo de la función social del arte, erradicando la idea que el arte pertenece a una elite que sería la única capaz de entender sus complejas formas de creación; ya que no se trata de distanciar a las audiencias de las técnicas artísticas, sino por el contrario, se trata de proponer espacios para construir la equidad en la valoración de los saberes, y repensar las relaciones sociales y los escenarios donde ocurren esos intercambios, estimulando la comprensión de lo invisible, más allá de las superposición de categorías segregadas y estrictamente delimitadas.

\section{Referencias Citadas}

Aguado, T., et al.

2002 Guía Inter. Una guía Práctica Para Aplicar la Educación Intercultural en la Escuela. Secretaría General Técnica. Subdirección de Información y Publicaciones, España.

Aguado, T.

2008 Educación Intercultural en FETE-UGT (Ed) Glosario. Educación Intercultural (pp. 1-4). Con Ética, Madrid.

Arana Grajales, T.

2007 El Concepto de teatralidad. Revista Artes, la revista 13: 79-89. Universidad de Antioquía, Colombia.
Aristóteles

2009 Poética. Ediciones Colihue S.R.L, Argentina.

Besalú, X.

2010 La Educación intercultural y el currículo escolar. http:// aulaintercultural.org/2010/02/26/la-educacion-interculturaly-el-curriculo-escolar/ (15 de junio de 2014)

Brook, $\mathrm{P}$

1994 La cultura de los lazos. En Tendencias Interculturales y Práctica Escénica, editado por P. Pavis y G. Rosa, pp. 99103. Grupo Editorial Gaceta S.A, México. 
Brook, P.

2000 El Espacio Vacío. Arte y Técnica del Teatro. Ediciones Península S.A., Barcelona.

Fischer-Lichte, E.

1994 Las tendencias interculturales en el teatro. En Tendencias Interculturales y Práctica Escénica, editado por P. Pavis, y G. Rosa, pp. 37-52. Grupo Editorial Gaceta S.A., México. Maturana, $\mathrm{H}$.

2013 Emociones y Lenguaje en Educación y Política. JC Saéz S.A., Chile.

Pavis, $\mathrm{P}$.

1994 ¿Hacia una teoría de la interculturalidad en el teatro? En Tendencias Interculturales y Práctica Escénica, editado por P. Pavis y G. Rosa, pp. 325-347. Grupo Editorial Gaceta

Pavis, $\mathrm{P}$.

2000 El Análisis de los Espectáculos. Teatro, mimo, danza, cine. Paidós Comunicación 121, Barcelona. S.A., México.

Reinelt, J.

2011 The Promise of Documentary. En Get Real. Documentary Theatre Past and Present Forsyth, editado por A. Forsyth \& C. Megson pp. 6-23. Palgrave Macmillan, Estados Unidos.

Sagástegui, D.

Una apuesta por la cultura: el aprendizaje situado. http:// www.redalyc.org/articulo.oa?id=99815918005 (12 de abril 2015)

Schechner, R.

1994 El interculturalismo y la elección de la cultura. En Tendencias interculturales y Práctica Escénica, editado por P. Pavis y G. Rosa, pp. 53-63. Grupo Editorial Gaceta S.A., México.

Ubersfeld, A.

1996 La Escuela del Espectador. Asociación de Directores de Escena de España, Madrid.

\section{Notas}

1 Información obtenida de la entrevista realizada a Marisol Vega, el 27 de febrero de 2014.

2 Reflexión surgida a partir de la entrevista realizada a Marisol Vega, el 27 de febrero de 2014.
Información obtenida de la entrevista realizada a Marisol Vega, el 27 de febrero de 2014.

4 Entrevista realizada a Paula González en Santiago de Chile, el 24 de enero de 2013. 